\title{
Synovial Tissue Response to Treatment in Psoriatic Arthritis
}

\author{
Veronica Codullo $^{1,2}$ and Iain B. McInnes ${ }^{*}, 1$ \\ ${ }^{1}$ University of Glasgow, $U K$ \\ ${ }^{2}$ University of Pavia, Italy
}

\begin{abstract}
Following its validation and wide application in rheumatoid arthritis (RA), synovial tissue analysis has recently been applied to studies on Psoriatic Arthritis (PsA). Such studies aim to thereby clarify its distinctive features and the nature of specific responses upon administration of disease modifying anti-rheumatic drug (DMARD) or biologic agents. In consequence, insights to disease pathogenesis, drugs' mechanisms of action (MOA) and biomarkers of response have emerged. Data from pilot and open-label studies, and recently from randomized controlled trials, have helped in refining the therapeutic approaches to PsA patients, by improving understanding of MOA and in provision of biomarkers of response. The availability of less invasive and reproducible analysis techniques to obtain and evaluate synovial biopsies will further enhance the utility of this approach in due course.
\end{abstract}

Keywords: Biologic therapy, psoriatic arthritis, biomarker, synovial tissue,

\section{INTRODUCTION}

Psoriatic arthritis (PsA) is a chronic inflammatory disease classified amongst spondyloarthropathies (SpA) and affecting patients with either concomitant cutaneous psoriasis or a personal or family history of the same [1]. Clinical presentation of PsA is heterogeneous, variably involving synovium of peripheral joints, spine and/or entheses [2]. Patients with PsA may develop articular structural damage both in terms of erosions and new bone formation, and may also develop systemic complications including the development of metabolic syndrome and increased cardiovascular risk with concomitant reduced life expectancy $[3,4]$. To avoid or at least reduce these complications and to improve patients' quality of life, the application of an appropriate and prompt treatment approach is mandatory. Ideally such therapeutics would be targeted to those patients most likely to benefit and least likely to develop toxicity. The synovium in PsA represents a primary target of disease pathogenesis, together with the skin, thus it is an intriguing and plausible site at which to explore important mechanisms of disease. Accordingly, evaluation of synovial tissues may assist identification of a drug's local mechanism(s) of action, the stratification of patients more likely to achieve a beneficial effect from a given therapy and the definition of new targets and their effectiveness [1,5]. With respect to the latter, it is conceivable that tissue changes early after an intervention may prove predictive of future efficacy and as such could improve early 'go/no-go' decision making in drug development, thereby limiting patient exposure to either placebo or ineffective therapies.

\section{SYNOVIAL TISSUE ANALYSIS IN PSA}

The synovial membrane in PsA comprises a thickened lining layer containing fibroblast-like synoviocytes and

*Address correspondence to this author at the Glasgow Biomedical Research Centre, University of Glasgow, 120 University Place, Glasgow, G12 8QQ, UK; Tel: +44 141330 8412; Fax: +44 141337 3217;

E-mail: i.b.mcinnes@clinmed.gla.ac.uk macrophages, overlying a deep interstitial inflammatory tissue within which are situated macrophages, $\mathrm{T}$ and $\mathrm{B}$ lymphocytes, NK cells, mast cells and widespread evidence of neovascularisation and to some extent lymphangiogenesis. In a substantial number of biopsies there are germinal centrelike reactions at present of unclear pathologic consequence. The advent of TNF blocking therapeutics provides ample evidence of the potential utility of synovial tissue as a resource for choosing novel therapeutic targets. Recently, pioneering studies lead by Tak, Bresnihan and others in the RA field have lead to the suggestion that synovial tissue may also provide a resource for biomarkers with predictive utility [6]. Thereby, trials in which synovial tissue is obtained upon a given intervention offer the potential advantage of requiring smaller patient group sizes than conventional phase IIa and IIb trials, with shorter follow-up to pivotal decisions [7]. At a technical level, studies in PsA have largely taken advantage of the validation of methods performed in RA synovial tissue analysis, both for obtaining synovial biopsies and the methods employed to analyse them [7]. Additional studies have also been initiated in the group of spondyloarthropathies as a whole [8]. Thus, the same techniques (arthroscopic and US-guided biopsy) and methods for immunohistologic assessment (manual count, semi-quantitative scores and digital image analysis) and molecular gene analysis (PCR, microarrays) that have contributed to the current knowledge on the pathobiology of inflammatory arthritides have been readily transferred to PsA [7, 9]. It is likely but must yet to be proven that the methodologies so far employed in RA will be readily applicable to PsA analyses. It is less clear however whether the same cellular or protein biomarkers will prove useful: the underlying conditions are tangibly different and several recent studies point to unique features of synovial tissue structure and composition between diseases. In particular, immunopathogenic appearances reveal similarities between SpA subgroups, for example comparing oligo- or polyarticular PsA, in terms of major histologic parameters (including lining layer thickness, vascularity, PMN, CD68+ 
and CD163+ lining and of sublining macrophages) [10]. This is also true when judged against their response to effective treatment [11]. Nevertheless subtle but potentially functional differences could be critical in allowing a more precise stratification and tailoring of drug to individual patients [12, 13]. Furthermore, studies on the effect of interventions on PsA synovial tissue conducted thus far have been limited to small numbers of patients, incomplete evaluation of early and late follow-up time points and the lack of a specific measure of disease activity in PsA. This in turn reflects imperfect validation of the DAS28 and ACR response criteria in clinical trials of PsA [14]. These issues might have affected the specificity of the results and further investigations should be encouraged.

Nevertheless, available data on the local synovial effect of different classes of drugs in PsA have provided insights on the mechanism of action of conventional DMARDs and new biological agents, contributing to effective improvement of clinical practice and understanding of PsA synovial pathobiology. We summarise such data below (see also Table 1). thickness of the lining layer. Analogously to what happens in RA synovitis [16], the change in CD68+ cell sublining infiltration correlated strongly and significantly with parameters of systemic inflammation such as ESR. An additional effect of MTX was to significantly reduce the expression of adhesion molecules such as VCAM, ICAM and E-selectin on sublining area vessels.

The immunobiology of PsA synovitis and its modifications after MTX were also investigated by a comparative analysis of the $\mathrm{T}$ cell receptor (TCR) repertoire in synovial tissue biopsies and paired synovial fluid (SF) and peripheral blood (PB) [17]. This analysis revealed that an effective response, again determined by a significant improvement in RAI, swollen joint count and DAS, was mirrored by a substantial decrease in the polyclonal component of the synovial $\mathrm{T}$ cell infiltrate, representing in turn a major component of the inflammatory infiltrate. A smaller decrease was also detected in the oligoclonal $\mathrm{T}$ cell populations. Most of the TCR clones that were exclusively found in the inflamed tissue did not survive after treatment while a small subset of clones could be persistently detected

Table 1. Local Synovial Effect Induced in PsA Clinical Trials

\begin{tabular}{|c|c|c|c|}
\hline Compound & Main Target & Effect on Psoriatic Synovium & Refs. \\
\hline Methotrexate & $\begin{array}{l}\text { T lymphocytes } \\
\text { Macrophages } \\
\text { ? others }\end{array}$ & $\begin{array}{l}\text { Reduction of synovial layer thickness } \\
\text { Reduction of CD3, CD4, CD8, CD68 sublining } \\
\text { infiltration } \\
\text { Reduction of polyclonal, inflammation-related CD4+ T } \\
\text { cells, smaller effect on oligoclonal CD8 T cells }\end{array}$ & {$[15,17]$} \\
\hline Infliximab & TNF & $\begin{array}{l}\text { Reduction of synovial layer thickness } \\
\text { Reduction of vascularity and endothelial cell activation }\end{array}$ & {$[22-24,26,28]$} \\
\hline Adalimumab & TNF & $\begin{array}{l}\text { Reduction of the synovial layer thickness } \\
\text { Reduction of CD3 infiltration } \\
\text { Reduction of MMP-13 expression }\end{array}$ & {$[27]$} \\
\hline Etanercept & TNF, lymphotoxin & $\begin{array}{l}\text { Reduction of the synovial layer thickness } \\
\text { Reduction of CD68+ and CD163+ macrophages } \\
\text { Reduction of MMP-3 and MMP-9 }\end{array}$ & [11] \\
\hline
\end{tabular}

\section{DMARDS - EFFECT ON SYNOVIAL TISSUE}

Various DMARDs including sulphasalazine, leflunomide and methotrexate (MTX) are widely used in general clinical practice to treat PSA. There remains however a rather sparse placebo-controlled literature that supports their efficacy in terms of ameliorating signs and symptoms and structural progression [1]. Studies demonstrating the synovial effect of such drugs are particularly scarce. Most evidence comes from patients treated with MTX. Its effect was evaluated on the synovial leukocyte infiltrate and mRNA and protein levels of several $\mathrm{T}$ cell- and macrophage-derived cytokines in a study of a small group of PsA patients [15]. Synovial biopsies were taken before MTX initiation and at various follow-up time-points (6-18 months). All patients showed a clinically significant improvement by means of Ritchie articular index (RAI), swollen joint count and disease activity score (DAS). The synovial changes paralleling this response showed reduced expression of CD3, CD4, CD8 and CD68 in the sublining area as well as a reduction in the in the tissue. The latter also showed clonal expansion in other compartments such as SF and PB. These cells were identified by transcripts of the CD8 lineage. Their high homology suggested a possible antigen-driven process, commensurate with previous results obtained by clonal analysis of TCR in isolated lymphocytes from actively inflamed PSA SF [18]. The differential modulation of an effective therapy might suggest different functions for these clones, the MTX-responsive being inflammation-related and the MTX-resistant having a more consistent role in pathogenetic mechanisms. Indeed, despite the small number of patients included and the pragmatic definition of efficacy (no formal ACR or EULAR response core sets are given in both studies and MTX effect is evaluated at different followup time points), these results provide compelling evidence that MTX directly modulates the inflammatory infiltrate in PsA. Moreover they point to a major contribution of $\mathrm{T}$ cells, and the CD8 subset in particular, to PsA pathogenesis and chronicity. 
To assess the potential beneficial effect of a lymphocytedepleting drug, a study of the synovial infiltrate in PsA patients treated with the fludarabine was performed [19]. PsA patients responded only modestly to fludarabine after 16 weeks of treatment, and did not perform significantly better than placebo when ACR20 response were calculated. This was reflected by a limited effect on infiltrating $T$ lymphocytes and E-selectin endothelial expression. Furthermore, no changes in the CD14+ component of the synovial inflammatory cells or on P-selectin could be detected. This stable presence of infiltrating macrophages and the persistence of a memory $\mathrm{T}$ cell subset that was presumably resistant to depletion (reflected also by the increased memory/naïve $\mathrm{T}$ cell ratio in $\mathrm{PB}$ ), provide indirect supportive evidence for the concept, also proven for RA [20], that local biomarkers may assist in the evaluation of a therapeutic regimen, even in small groups of patients. Accordingly, results from cross-sectional studies show that when a conventional treatment (e.g. with MTX) fails to achieve an adequate response in PsA patients that show active disease despite treatment, features of synovitis are not significantly different when compared to patients who do not receive any therapy [10], and the lack of response is reflected by persistence of inflammation [21].

\section{BIOLOGICAL AGENTS - EFFECT ON SYNOVIAL TISSUE}

The advent of biological therapies has had a significant impact on the treatment strategies whereby PsA is managed. TNF-alpha inhibitors have proven efficacious in PsA in reducing signs and symptoms of synovitis, improving patient-reported outcomes (Health Assessment Questionnaire, physical function, Quality of Life, and fatigue) and suppressing radiographic progression [1]. Synovial tissue analysis before and after anti-TNF-alpha therapy provides direct proof of their local efficacy and by inference their mode of action [5]. A further rationale to multiple and serial sampling of the PsA synovial tissue has been to obtain reliable biomarkers to be applied in the assessment of the newly developed agents. Several openlabel trials have clearly provided evidence for cellular and angiogenic changes in both PsA and other SpA subsets [2224]. In particular, evidence from these analyses provides concordant results. In PsA synovium, as previously indicated in RA [25], TNF blockade significantly reduces infiltration of sublining CD68+ macrophages and CD3+ T lymphocytes within 48 hours, and the effect is not achieved by influencing apoptotic homeostasis in the synovium, assessed by TUNEL and caspase-3 analysis [26]. A likely mechanism of action therefore is via "deactivation" of the endothelium [23]. Indeed, although the effect on the endothelium was not evaluated at the same very early time-point, after 4 weeks of therapy with low-dose infliximab, a significant reduction in the expression of ICAM-1 on synovial capillaries could be observed, with VCAM and E-selectin showing the same trend [23]. In parallel, the same study showed that vascularity itself was decreased and that synovial expression of pro-angiogenic factors, such as von Willebrand factor and VEGF, and of markers of neovascularization, namely av $\beta 3$ integrin, were down-regulated. Similarly, in a distinct trial of PsA patients treated with infliximab, significant reduction in CD68+ lining and sublining macrophages was observed after
8 weeks [24]. In parallel, a decrease in vascularity was observed, that was mainly explained by a lower proportion of $\alpha v \beta 3$-integrin neovessels in treated patients and accompanied by histologic and molecular down-modulation of VEGF and its receptors, VEGFR-1 and -2. Moreover, the chemokine SDF-1 showed significantly reduced vascular expression [24].

Recently, a randomized, double blind, placebo-controlled trial with adalimumab has confirmed and reinforced previous results in open-label and smaller trials by comparing synovial tissue histology before and after a short course of treatment [27]. In this study, clinical efficacy assessed by DAS28, EULAR and ACR responses, was paralleled by a significant reduction of infiltrating CD3 + T lymphocytes, with CD68+ and CD163+, lining and sublining, total and resident macrophages also showing a reducing trend. A marked reduction in MMP-3 and MMP-13 expression after treatment was also demonstrated. By covariance analysis of all the tested variables, and thus taking into account the inter-patient variability and baseline differences already present despite randomization, the decrease in $\mathrm{CD} 3+\mathrm{T}$ cell infiltration and in MMP-13 expression still significantly reflected changes induced by the TNF-alpha inhibitor. These results again point out the importance of $\mathrm{T}$ cells in PsA pathobiology and suggest CD3+ cells and MMP-13 as synovial biomarkers of response to effective treatments.

TNF blockade may also influence the presence of ectopic lymphoid aggregates that resemble secondary lymphoid organs (lymphoneogenetic (LN) structures), occurring in RA and recently described also in PsA [28]. A histologic analysis showed persistence of LN features over the course of TNF-alpha blockade in non-responders patients and their regression in those undergoing clinical remission. Although the small numbers recruited and the preliminary nature of this study preclude definitive conclusion, in light of recent data in RA showing a reversal of $\mathrm{LN}$ in patients who achieved a good EULAR response after a short course of anti-TNF-alpha therapy [29], LN features could represent a valuable biomarker of response and deserve further analysis in PsA.

Tissue biomarkers and their modification following additional immuno-modulatory treatments have been explored in other trials. Thus, after administration of recombinant IL-10 in PsA patients [30], in a study designed to assess safety and tolerability of the drug (not powered to detect a significant clinical effect of the drug on articular disease) the synovial tissue showed a significant reduction in CD3+ $\mathrm{T}$ lymphocytes and CD68+ lining and sublining macrophages, together with a decreased proportion of $\mathrm{P}$ selectin + vessels and a down-regulation of vascular $\alpha v \beta 3$ integrin [30]. Similarly, the effect of alefacept, a recombinant protein that blocks the interaction between LFA3 and CD2 and subsequently inhibits $\mathrm{T}$ cell activation and proliferation, has been evaluated in PsA synovium in a small open-label trial [31]. Alefacept induced a local significant reduction of effector $\mathrm{T}$ cells and of sublining macrophages, with a pronounced response, in the $\mathrm{CD} 45 \mathrm{RO}+$ $\mathrm{T}$ lymphocyte memory subset. More recently, the synovial tissue response to abatacept, a CTLA4-Ig fusion protein, has been also described in a case report of a patient with severe refractory PsA [32]. Interference with co-stimulatory 
pathways was efficacious in terms of clinical parameters of the patient joint and skin disease and in inducing reduction of synovial infiltration of CD15+ lining neutrophils, CD68+ sublining macrophages and CD3 + T lymphocytes.

\section{DIFFERENTIAL RESPONSE TO THERAPY OF SYNOVIUM AND SKIN}

The presence of a simultaneous cutaneous and articular disease and the relative ease of access to both target sites make it possible to compare the local effect of drugs in different tissue compartments. Cutaneous psoriatic lesions are characterized by keratinocyte proliferation, an inflammatory infiltrate driven by a cytokine and chemokine network and endothelial activation with enhanced adhesion molecule and integrin expression [33]. Despite differences in embryonic origin, the resident cellular components of the two tissues and the pathological lesions share common features, cytokine expression patterns and TCR oligoclonal expansion [34]. Moreover, strong similarities can be derived from the mechanisms of action and local effect of the same drugs. Indeed, immune modulation by use of conventional agents (for example MTX, cyclosporine) and of the more recent biologic agents (anti-TNF alpha agents primarily) has proven efficacious in psoriasis as in PsA by means of reduced vascularity, endothelial cells activation and inflammatory cell infiltration [23]. Nonetheless, studies directly comparing effects of drugs on both tissues have occasionally revealed discrepancy between skin and synovium responses, especially when the efficacy of the drug was limited overall or the dosage of the drug was suboptimal for one compartment $[19,23,30]$. These differential responses and their biological basis have not been clarified as yet and require further investigation. Beside pharmacokinetic explanations, biologic mechanisms for discrepant responses have been proposed. For example apoptosis of dermal CD11c+ DCs can be induced by TNFalpha blockade in psoriatic skin responsive to treatment [35]. The same effect has not been documented in the synovium, where apoptosis is not thought to be a major contributor to the reduction of the inflammatory infiltrate [25] and where understanding the functional importance of the different DC subsets remains controversial [36-38]. A reduction in $\mathrm{PB}$ levels of DCs, and plasmacytoid DCs (pDCs) in particular, has been demonstrated along with their selective accumulation in inflamed peripheral tissues [36]. It has also been recently suggested that pDCs might exert local antiinflammatory activities, since their depletion was detrimental in a model of experimental arthritis [38]. Case reports have accordingly shown an increase in circulating pDCs following an effective DMARDs combination therapy [39], but data so far are limited and deserve further elucidation. Indeed, specifically investigating the role of effective therapies in modulating DCs, their different phenotypes, maturation states and circulating pathways will provide a valuable insight into how skin and articular lesions are interconnected.

\section{CONCLUDING REMARKS}

The ability to perform short-term early phase clinical trials has become crucial in the last few years because of the increasing numbers of drugs developed to treat inflammatory arthritides, including PsA, in a more aggressive, specific and efficient way. The analysis of synovial tissue has rendered such studies feasible. The validation of minimally invasive and repeatable techniques for synovial tissue biopsy has provided a direct insight into the tissue target of the disease. This pertains to understanding pathogenic mechanisms and to the development of sensitive biomarkers of response. Future studies in PsA are now required to complement the growing evidence base in RA and maximise the yield from this new investigative approach.

\section{REFERENCES}

[1] Ritchlin CT, Kavanaugh A, Gladman DD, et al. Treatment recommendations for psoriatic arthritis. Ann Rheum Dis 2009; 68: $1387-94$.

[2] Taylor W, Gladman D, Helliwell P, Marchesoni A, Mease P, Mielants H. Classification criteria for psoriatic arthritis: development of new criteria from a large international study. Arthritis Rheum 2006; 54: 2665-73.

[3] Wong K, Gladman DD, Husted J, Long JA, Farewell VT. Mortality studies in psoriatic arthritis: results from a single outpatient clinic. I. Causes and risk of death. Arthritis Rheum 1997; 40: 1868-72.

[4] Gladman DD. Mortality in psoriatic arthritis. Clin Exp Rheumatol 2008; 26: S62-5.

[5] Bresnihan B, Baeten D, Firestein GS, et al. Synovial tissue analysis in clinical trials. J Rheumatol 2005; 32: 2481-4.

[6] Gerlag D, Tak PP. Novel approaches to the treatment of rheumatoid arthritis: lessons from the evaluation of synovial biomarkers in clinical trials. Best Pract Res Clin Rheumatol 2008; 22: 311-23.

[7] Gerlag D, Tak PP. How to perform and analyse synovial biopsies. Best Pract Res Clin Rheumatol 2009; 23: 221-32.

[8] Rihl M, Baeten D, Seta N, et al. Technical validation of cDNA based microarray as screening technique to identify candidate genes in synovial tissue biopsy specimens from patients with spondyloarthropathy. Ann Rheum Dis 2004; 63: 498-507.

[9] Smith MD, Baeten D, Ulfgren AK, et al. OMERACT Synovial Special Interests Group. Standardisation of synovial tissue infiltrate analysis: how far have we come? How much further do we need to go? Ann Rheum Dis 2006; 65: 93-100.

[10] Kruithof E, Baeten D, De Rycke L, et al. Synovial histopathology of psoriatic arthritis, both oligo- and polyarticular, resembles spondyloarthropathy more than it does rheumatoid arthritis. Arthritis Res Ther 2005; 7: R569-80.

[11] Kruithof E, De Rycke L, Roth J, et al. Immunomodulatory effects of etanercept on peripheral joint synovitis in the spondylarthropathies. Arthritis Rheum 2005; 52: 3898-909.

[12] Danning CL, Illei GG, Hitchon C, Greer MR, Boumpas DT, McInnes IB. Macrophage-derived cytokine and nuclear factor kappaB p65 expression in synovial membrane and skin of patients with psoriatic arthritis. Arthritis Rheum 2000; 43: 1244-56.

[13] Boyle DL, Kavanaugh A. The pathobiology of psoriatic synovium. Curr Opin Rheumatol 2008; 20: 404-7.

[14] Fransen J, Antoni C, Mease PJ, et al. Performance of response criteria for assessing peripheral arthritis in patients with psoriatic arthritis: analysis of data from randomised controlled trials of two tumour necrosis factor inhibitors. Ann Rheum Dis 2006; 65: 13738.

[15] Kane D, Gogarty M, O'leary J, et al. Reduction of synovial sublining layer inflammation and proinflammatory cytokine expression in psoriatic arthritis treated with methotrexate. Arthritis Rheum 2004; 50: 3286-95.

[16] Haringman JJ, Gerlag DM, Zwinderman AH, et al. Synovial tissue macrophages: a sensitive biomarker for response to treatment in patients with rheumatoid arthritis. Ann Rheum Dis 2005; 64: 8348.

[17] Curran SA, FitzGerald OM, Costello PJ, et al. Nucleotide sequencing of psoriatic arthritis tissue before and during methotrexate administration reveals a complex inflammatory $\mathrm{T}$ cell infiltrate with very few clones exhibiting features that suggest they drive the inflammatory process by recognizing autoantigens. J Immunol 2004; 172: 1935-44.

[18] Costello PJ, Winchester RJ, Curran SA, et al. Psoriatic arthritis joint fluids are characterized by CD8 and CD4 $\mathrm{T}$ cell clonal expansions appear antigen driven. J Immunol 2001; 166: 2878-86. 
[19] Takada K, Danning CL, Kuroiwa T, et al. Lymphocyte depletion with fludarabine in patients with psoriatic arthritis: clinical and immunological effects. Ann Rheum Dis 2003; 62: 1112-5.

[20] Baeten D, Houbiers J, Kruithof E, et al. Synovial inflammation does not change in the absence of effective treatment: implications for the use of synovial histopathology as biomarker in early phase clinical trials in rheumatoid arthritis. Ann Rheum Dis 2006; 65: 990-7.

[21] van Kuijk AW, Reinders-Blankert P, Smeets TJ, Dijkmans BA, Tak PP. Detailed analysis of the cell infiltrate and the expression of mediators of synovial inflammation and joint destruction in the synovium of patients with psoriatic arthritis: implications for treatment. Ann Rheum Dis 2006; 65: 1551-7.

[22] Baeten D, Kruithof E, Van den Bosch F, et al. Immunomodulatory effects of anti-tumor necrosis factor alpha therapy on synovium in spondylarthropathy: histologic findings in eight patients from an open-label pilot study. Arthritis Rheum 2001; 44: 186-95.

[23] Goedkoop AY, Kraan MC, Picavet DI, et al. Deactivation of endothelium and reduction in angiogenesis in psoriatic skin and synovium by low dose infliximab therapy in combination with stable methotrexate therapy: a prospective single-centre study. Arthritis Res Ther 2004; 6: R326-34.

[24] Cañete JD, Pablos JL, Sanmartí R, et al. Antiangiogenic effects of anti-tumor necrosis factor alpha therapy with infliximab in psoriatic arthritis. Arthritis Rheum 2004; 50: 1636-41.

[25] Smeets TJ, Kraan MC, van Loon ME, Tak PP. Tumor necrosis factor alpha blockade reduces the synovial cell infiltrate early after initiation of treatment, but apparently not by induction of apoptosis in synovial tissue. Arthritis Rheum 2003; 48: 2155-62.

[26] Goedkoop AY, Kraan MC, Teunissen MB, et al. Early effects of tumour necrosis factor alpha blockade on skin and synovial tissue in patients with active psoriasis and psoriatic arthritis. Ann Rheum Dis 2004; 63: 769-73.

[27] van Kuijk AW, Gerlag DM, Vos K, et al. A prospective, randomized, placebo-controlled study to identify biomarkers associated with active treatment in psoriatic arthritis: effects of adalimumab treatment on synovial tissue. Ann Rheum Dis 2009; 68: 1303-9.

[28] Cañete JD, Santiago B, Cantaert T, et al. Ectopic lymphoid neogenesis in psoriatic arthritis. Ann Rheum Dis 2007; 66: 720-6.
[29] Cañete JD, Celis R, Moll C, et al. Clinical significance of synovial lymphoid neogenesis and its reversal after anti-tumour necrosis factor alpha therapy in rheumatoid arthritis. Ann Rheum Dis 2009; 68: 751-6.

[30] McInnes IB, Illei GG, Danning CL, et al. IL-10 improves skin disease and modulates endothelial activation and leukocyte effector function in patients with psoriatic arthritis. J Immunol 2001; 167: 4075-82.

[31] Kraan MC, van Kuijk AW, Dinant HJ, et al. Alefacept treatment in psoriatic arthritis: reduction of the effector $\mathrm{T}$ cell population in peripheral blood and synovial tissue is associated with improvement of clinical signs of arthritis. Arthritis Rheum 2002; 46: $2776-84$

[32] Cañete JD, Celis R, Hernandez V, Pablos JL, Sanmartí R. Synovial immunopathological changes associated with successful abatacep therapy in a case of severe refractory pasoriatic arthritis. Ann Rheum Dis 2010; 69: 935-6.

[33] Nickoloff BJ, Nestle FO. Recent insights into the immunopathogenesis of psoriasis provide new therapeutic opportunities. J Clin Invest 2004; 113: 1664-75.

[34] Tassiulas I, Duncan SR, Centola M, Theofilopoulos AN, Boumpas DT. Clonal characteristics of T cell infiltrates in skin and synovium of patients with psoriatic arthritis. Hum Immunol 1999; 60: 479-91.

[35] Malaviya R, Sun Y, Tan JK, et al. Etanercept induces apoptosis of dermal dendritic cells in psoriatic plaques of responding patients. J Am Acad Dermatol 2006; 55: 590-7.

[36] Jongbloed SL, Lebre MC, Fraser AR, et al. Enumeration and phenotypical analysis of distinct dendritic cell subsets in psoriatic arthritis and rheumatoid arthritis. Arthritis Res Ther 2006; 8: R15.

[37] Lebre MC, Jongbloed SL, Tas SW, Smeets TJ, McInnes IB, Tak PP. Rheumatoid arthritis synovium contains two subsets of CD83DC-LAMP-dendritic cells with distinct cytokine profiles. Am J Pathol 2008; 172: 940-50.

[38] Jongbloed SL, Benson RA, Nickdel MB, Garside P, McInnes IB, Brewer JM. Plasmacytoid dendritic cells regulate breach of selftolerance in autoimmune arthritis. J Immunol 2009; 182: 963-8

[39] Sugita K, Hino R, Ogata M, Kabashima K, Tokura Y. Fluctuation of circulating plasmacytoid dendritic cells in a patient with psoriatic arthritis. J Eur Acad Dermatol Venereol 2008; 22: 1365-6.

(C) Codullo and McInnes; Licensee Bentham Open

This is an open access article licensed under the terms of the Creative Commons Attribution Non-Commercial License (http://creativecommons.org/licenses/by-nc/ $3.0 /$ ) which permits unrestricted, non-commercial use, distribution and reproduction in any medium, provided the work is properly cited. 